\title{
KRI-1314: An Orally Effective Inhibitor of Human Renin
}

\author{
Yasuo Etoh ${ }^{1}$, Mizuo Miyazaki ${ }^{1, *}$, Hiroshi Saitoh ${ }^{1}$ and Noboru Toda ${ }^{2}$ \\ 'Department of Pharmacology, Osaka Medical College, 2-7 Daigakumachi, Takatsuki, Osaka 569, Japan \\ ${ }^{2}$ Department of Pharmacology, Shiga University of Medical Sciences, Seta, Ohtsu, Shiga 520-21, Japan \\ Received March 19, 1993 Accepted June 22, 1993
}

\begin{abstract}
Biochemical and pharmacological properties of KRI-1314, a newly synthesized, low molecular weight (M.W.: 690) renin inhibitor, were investigated in vitro and in vivo. The novel amino acid norstatine, which is shorter in chain length than the well-known statine, was incorporated into KRI-1314 as a tetrahedral transition-state analogue for the $\mathrm{Leu}^{10}-\mathrm{Val}^{11}$ scissile peptide in the renin substrate. KRI-1314 more strongly inhibited plasma renins from primates than those from dogs, rabbits, guinea pigs and rats. KRI-1314 competitively inhibited highly-purified human renin with a $\mathrm{K}_{\mathrm{i}}$ value of $9.9 \times 10^{-10} \mathrm{M}$. KRI-1314 strongly inhibited the tissue renin-like activities of various organs from Japanese monkeys, with $\mathrm{IC}_{50}$ values on the order of $10^{-8} \mathrm{M}$. KRI-1314 was also very stable in various tissue homogenates from Japanese monkeys. Both intravenous (from 0.25 to $3 \mathrm{mg} / \mathrm{kg}$ ) and oral (10 and $30 \mathrm{mg} / \mathrm{kg}$ ) administration of KRI-1314 to anesthetized and conscious sodium-depleted Japanese monkeys, respectively, significantly lowered the blood pressure and plasma renin activity without affecting the heart rate. In Japanese monkeys, KRI-1314 was continuously detected in the plasma up to at least $7 \mathrm{hr}$ after oral administration of 10 and $30 \mathrm{mg} / \mathrm{kg}$. These results demonstrate that KRI-1314 is a highly potent, primate-selective and long-lasting oral renin inhibitor with a blood pressure lowering effect.
\end{abstract}

Keywords: Renin inhibitor, Orally effective, Hypotensive effect, Japanese monkey, Tissue renin-like activity

One of the specific ways of blocking the renin-angiotensin system (RAS) is to inhibit renin, which catalyzes the first and rate-limiting step in the generation of angiotensin II (Ang II). Such specific inhibition of the RAS could provide an opportunity to clarify the exact role of this system in the pathogenesis of hypertension. Moreover, it might also reduce the occurrence of side effects such as dry cough, urticaria and angioedema (1-3) that are thought to be induced by angiotensin converting enzyme (ACE) inhibitors, since ACE hydrolyzes not only angiotensin I (Ang I) to active Ang II but also bradykinin, substance $P$ and enkephalines to their individual inactive fragments (4).

In the late 1960 s, naturally occurring renin inhibitors such as a phospholipid (5) and pepstatins (6) were reported. Since that time, we have focused our attention on the development of a synthetic renin inhibitor and showed that phosphatidyl and phosphorylethanolamine derivatives $(7,8)$ and $N$-acetyl-pepstatin (9) inhibited the renin activity and lowered the blood pressure in hypertensive animals. Unfortunately, the potencies of these compounds

\footnotetext{
* To whom correspondence should be addressed.
}

were not high enough to inhibit human renin. Later, inhibitors having high and specific affinity for human renin were derived from renin substrate analogues. Szelke et al. (10) incorporated a reduced moiety $-\mathrm{CH}_{2}-\mathrm{NH}-$ in place of the $\mathrm{Leu}^{10}-\mathrm{Val}^{11}$ scissile peptide bond in the analogous human renin substrate sequence to obtain non-hydrolyzable analogues of the tetrahedral transition state, e.g., H-142 with nanomolar range activity in vitro. On the other hand, Boger et al. (11) synthesized other potent renin inhibitors with $\mathrm{IC}_{50}$ values of $10^{-9}$ to $10^{-8} \mathrm{M}$ by incorporating an amino acid statine, $(3 S, 4 S)$-4-amino-3hydroxy-6-methyl-heptanoic acid, instead of the Leu ${ }^{10}$ $\mathrm{Leu}^{11}$ scissile dipeptide in the analogues of pig angiotensinogen. The $3 S$-hydroxyl moiety of this statine residue is assumed to mimic the transition state or tetrahedral intermediate (hydroxy isostere) of the enzyme reaction, thereby enabling efficient binding to renin (12). However, it is widely accepted that these peptide compounds are ineffective when orally administered, presumably because of their peptidic nature, high molecular weight and metabolic instability.

In 1986, we reported that a norstatine-containing dipeptide, KRI-1177, exerted a potent inhibitory effect on hu- 
man renin in vitro and reduced the blood pressure, plasma renin activity (PRA) and plasma concentrations of Ang I and II + III after intravenous injection in anesthetized, sodium-depleted Japanese monkeys (Macaca fuscata) (13). Furthermore, it was also demonstrated that oral administration of KRI-1230, a small norstatine-containing dipeptide, reduced the blood pressure and PRA in conscious, sodium-depleted Japanese monkeys (14). The shorter chain length amino acid norstatine, $(2 R, 3 S)$-3amino-2-hydroxy-5-methylhexanoic acid, contained in the structures of these compounds is thought to elevate the affinity of the inhibitors for the renin molecule and improve the bioavailability by reducing the molecular weight of the inhibitors to a greater extent than the naturally occurring amino acid statine $(15,16)$.

Recently, we developed the more potent cyclohexyl-norstatine-containing dipeptide KRI-1314, isopropyl ( $2 R$, $3 S)-3-\{N$-[2-(1-naphthylmethyl)-3-(morpholinocarbonyl)propionyl]-L-histidyl \}amino-4-cyclohexyl-2-hydroxybutyrate, having high enzyme specificity for human renin $(17,18)$. The present study describes further detailed biochemical and pharmacological properties of this novel human renin inhibitor.

\section{MATERIALS AND METHODS}

\section{Drugs and chemicals}

The renin inhibitor KRI-1314 (Fig. 1) and phenylalanyl-alanyl-proline (Phe-Ala-Pro) (19) were synthesized by
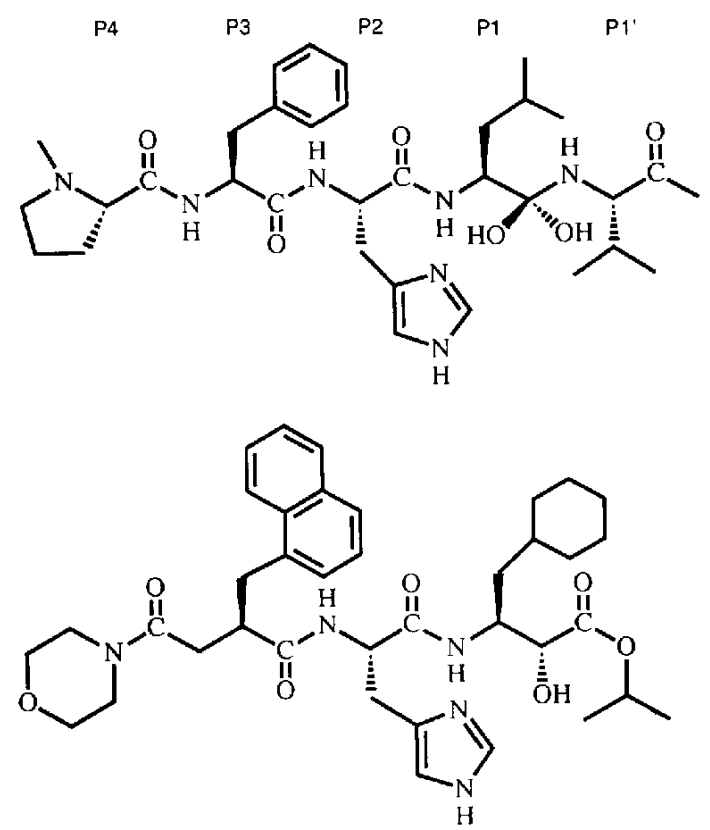

Fig. 1. Chemical structure of the human angiotensinogen transition-state fragment (upper, -Pro $-\mathrm{Phe}^{8}-\mathrm{His}^{9}-\mathrm{Leu}^{10}-\mathrm{Val}^{11}$-) and KRI1314 (lower, M.W.: 689.85).
Kissei Pharmaceutical Co., Ltd. (Matsumoto). Purified human renin (20) was generously provided by Prof. Kazuo Murakami of the University of Tsukuba (Ibaraki). Neomycin sulfate, bovine serum albumin (BSA) and phenylmethylsulfonylfuoride (PMSF) were purchased from Sigma Chemical Co. (St. Louis, MO, USA). Leupeptin, bestatin, aspartyl-arginyl-valyl-tyrosyl-isoleucyl-histidyl-prolyl-phenylalanyl-histidyl-leucyl-valyl-isoleucyl-histidine (Asp-Arg-Val-Tyr-Ile-His-Pro-Phe-HisLeu-Val-Ile-His, human tridecapeptide renin substrate) and succinyl-arginyl-prolyl-phenylalanyl-histidyl-leucylleucyl-valyl-tyrosine 4-methyl-coumaryl-7-amide (SucArg-Pro-Phe-His-Leu-Leu-Val-Tyr-MCA, MCA renin substrate) were purchased from Peptide Institute, Inc. (Osaka). Captopril and ketamine hydrochloride were purchased from Sankyo Co., Ltd. (Tokyo). Renin Riabead kits, sodium pentobarbital and furosemide were purchased from Dainabot Co., Ltd. (Tokyo), Dainippon Pharmaceutical Co., Ltd. (Osaka) and Hoechst Japan Ltd. (Tokyo), respectively. All other reagents and solvents were of analytical grade.

For the in vitro experiments, KRI-1314 was dissolved at various concentrations in $\mathbf{9 9 \%}$ dimethylsulfoxide (DMSO).

\section{Assay procedure for enzyme inhibition in vitro}

Human plasma samples with high renin activity were obtained from patients with pseudo-Bartter syndrome who presented with symptoms of hypokalaemia, hyperreninaemia, hyperaldosteronism and normal blood pressure with diuretic abuse. In Japanese monkeys (Macaca fuscata), rhesus monkeys (Macaca mulatta), cynomolgus monkeys (Macaca fascicularis), mongrel dogs, albino rabbits, guinea pigs and Wistar rats, sodium depletion was carried out to obtain high renin plasma. The animals were fed on a specially formulated low-sodium diet every day and given furosemide $(2 \mathrm{mg} / \mathrm{kg}$, intramuscularly in monkeys and $15 \mathrm{mg} / \mathrm{kg}$, orally in other animals) every 2 days for a week. One day after the final dose, blood was collected into chilled tubes containing ethylenediaminetetraacetic acid disodium salt (EDTA-2 $\mathrm{Na}$ ) at a final concentration of $2.7 \mathrm{mM}$ as an anticoagulant and then centrifuged at $1200 \times \mathrm{g}$ for $15 \mathrm{~min}$. The plasma was separated and stored at $-20^{\circ} \mathrm{C}$. Pooled plasma yielded 5 to $25 \mathrm{ng}$ Ang $\mathrm{I} / \mathrm{ml}$ of plasma after a 60 min incubation at $37^{\circ} \mathrm{C}$.

The plasma renin inhibitory activity assay was conducted in a medium adjusted to either $\mathrm{pH} 6.0$ (optimal) or $\mathrm{pH}$ 7.4 (physiological). The medium consisted of $0.5 \mathrm{ml}$ of pooled plasma containing endogenous renin and angiotensinogen, $0.05 \mathrm{ml}$ of $20 \mathrm{mM}$ Phe-Ala-Pro as an ACE inhibitor, $0.35 \mathrm{ml}$ of $0.5 \mathrm{M}$ sodium phosphate buffer containing $0.3 \%$ neomycin sulfate and $14 \mathrm{mM}$ EDTA $2 \mathrm{Na}$, and 0.1 
ml of KRI-1314 solution at various concentrations or 99\% DMSO as a control. One half of the reaction mixture was maintained in an ice bath, and the remainder was incubated for $30 \mathrm{~min}$ at $37^{\circ} \mathrm{C}$. After the reaction had ceased following rapid cooling in the ice bath, the rate of Ang I production was measured by radioimmunoassay using a commercial assay kit (Renin Riabead kit). PRA was expressed as $\mathrm{ng}$ Ang $\mathrm{I} / \mathrm{ml}$ per hr.

The kinetic study of human renin inhibition was carried out with human renin and a synthetic human renin substrate. The assay mixture consisted of $0.12 \mathrm{ml}$ of 0.1 $\mathrm{M}$ Tris- $\mathrm{HCl}$ buffer ( $\mathrm{pH} 7.5$ ) containing $0.25 \%$ BSA, $0.015 \mathrm{ml}$ of purified human renin ( $5 \mathrm{~m}$ Goldblatt units $/ \mathrm{ml}$ of $0.1 \%$ BSA), $0.03 \mathrm{ml}$ of either 21.5 or $32.2 \mu \mathrm{M}$ human tridecapeptide substrate in $0.1 \mathrm{M}$ Tris- $\mathrm{HCl}$ buffer $(\mathrm{pH}$ $7.5), 0.015 \mathrm{ml}$ of $20 \mathrm{mM}$ Phe-Ala-Pro as an ACE inhibitor, $0.12 \mathrm{ml}$ of distilled water and $0.03 \mathrm{ml}$ of KRI-1314 solution at various concentrations or $99 \%$ DMSO as a control. The mixture was incubated for $15 \mathrm{~min}$ at $37^{\circ} \mathrm{C}$, and the reaction was terminated by heating at $100^{\circ} \mathrm{C}$ for $5 \mathrm{~min}$. The rate of Ang I generation was measured by radioimmunoassay as described above. The mode of inhibition and the inhibition constant $\left(\mathrm{K}_{\mathrm{i}}\right)$ were determined by Dixon plots (21).

The inhibitory potency of KRI-1314 against tissue renin-like (Ang I-forming) activities of the kidney, heart, lung, adrenal and aorta from Japanese monkeys was examined. Tissues were rinsed with saline and homogenized with a Potter-Elvehjem homogenizer at 5 to 8 strokes per $30 \mathrm{sec}$ in a five-fold volume of ice-cold $0.1 \mathrm{M}$ sodium phosphate buffer (pH 7.4) containing $1 \mathrm{mM}$ EDTA $2 \mathrm{Na}, 12$ $\mu \mathrm{M}$ leupeptin, $1 \mathrm{mM}$ sodium tetrathionate dihydrate and $5 \mathrm{mM}$ PMSF. After centrifugation of each homogenate at $800 \times g$ for $10 \mathrm{~min}$, the supernatants were collected as tissue extracts. The assay medium consisted of $0.25 \mathrm{ml}$ of tissue extract (fifty-fold dilution for kidney only), $0.1 \mathrm{ml}$ of semi-purified sheep renin substrate ( $4000 \mathrm{ng}$ Ang I eq. $/ \mathrm{ml}$ ) prepared by the method described by Skinner (22), 0.53 $\mathrm{ml}$ of $0.1 \mathrm{M}$ sodium phosphate buffer ( $\mathrm{pH} 7.4)$ containing $35 \mu \mathrm{M}$ captopril, $10 \mathrm{mM}$ EDTA $\cdot 2 \mathrm{Na}, 15 \mu \mathrm{M}$ bestatin, 1 $\mathrm{mM}$ sodium tetrathionate and $0.1 \%$ neomycin sulfate, $0.02 \mathrm{ml}$ of $50 \mathrm{mM}$ PMSF, and $0.1 \mathrm{ml}$ of KRI-1314 solution at various concentrations or $99 \%$ DMSO as a control. The rate of Ang I production at $37^{\circ} \mathrm{C}$ was measured by radioimmunoassay as described above. The protein content of each tissue extract was measured by the dye binding method described by Bradford (23). Renin-like activities in each tissue homogenate were expressed as $\mathrm{ng}$ Ang $\mathrm{I} / \mathrm{mg}$ protein per $\mathrm{hr}$.

The in vitro enzyme inhibitory activity of KRI-1314 was expressed as a percentage of reduction of enzyme activity. The concentration of KRI-1314 producing $50 \%$ inhibition of enzyme activity was defined as the $\mathrm{IC}_{50}$.

\section{Stability in tissue homogenates}

The stability of KRI-1314 in various tissues was examined in the homogenates of the liver, lung, small intestine and kidney from Japanese monkeys. Tissues were rapidly cooled and washed twice in isotonic $1.15 \%$ potassium chloride solution. One gram of each tissue was homogenized with $4 \mathrm{ml}$ of chilled $1.15 \%$ potassium chloride solution and then filtered through gauze. The reaction mixture contained $0.5 \mathrm{ml}$ of $0.1 \mathrm{M}$ sodium phosphate buffer ( $\mathrm{pH} 7.4), 0.4 \mathrm{ml}$ of tissue homogenate and $0.1 \mathrm{ml}$ of $10^{-4}$ M KRI-1314 or MCA renin substrate dissolved in $99 \%$ DMSO. The reaction mixture was incubated at $37^{\circ} \mathrm{C}$, and the reaction was terminated after different time intervals by adding $4 \mathrm{ml}$ of methanol. Adequate amounts of supernatants were fractionated by high performance liquid chromatography (HPLC) on a TRI ROTAR-VI (Jasco, Tokyo), equipped with a column packed with TSK-GEL ODS-80 TM ( $4.6 \mathrm{mmID} \times 150 \mathrm{~mm}$; Tosoh, Tokyo). The column was eluted with a mixture of acetonitrile and 50 $\mathrm{mM}$ ammonium acetate solution $(1: 1, \mathrm{v} / \mathrm{v})$ at a rate of $1.3 \mathrm{ml}$ per min at $55^{\circ} \mathrm{C}$. KRI-1314 and the MCA renin substrate in the effluent were detected by ultraviolet absorption at $225 \mathrm{~nm}$. The data were calculated as percentages of the remaining concentrations of the compounds to the respective initial values.

In vivo experiments in sodium-depleted Japanese monkeys

Experimental model: In the experiments of both intravenous and oral administrations, sodium depletion was carried out to stimulate the endogenous RAS. Tame Japanese monkeys of either sex, weighing 7 to $11 \mathrm{~kg}$, were fed daily a sodium-deficient diet (salt-free bread and fruit) and given furosemide ( $2 \mathrm{mg} / \mathrm{kg}$, intramuscularly) every 2 days for a week. The final injection of furosemide was given 1 day before the experimental day. Under a oneweek sodium depletion regimen, the PRA of anesthetized Japanese monkeys rose significantly from $3.9 \pm 1.5$ to $23.2 \pm 3.1 \mathrm{ng}$ Ang $\mathrm{l} / \mathrm{ml}$ per $\mathrm{hr}(\mathrm{n}=7, \mathrm{P}<0.001)$ (13).

Measurement of blood pressure and heart rate: On the morning of both the intravenous and the oral experimental day, the sodium-depleted monkeys were anesthetized with ketamine hydrochloride $(10 \mathrm{mg} / \mathrm{kg}$, intramuscularly). A catheter was inserted into the femoral artery and then connected to a pressure transducer (LPU-0.1-350-I; Toyo-Baldwin, Tokyo) for continuous monitoring of blood pressure. Heart rate was monitored by a cardiotachometer triggered by arterial pressure pulsation. After the experiment, the femoral catheter was removed under anesthesia, and the puncture site was oppressed for hemostasis.

PRA assay: Blood samples for the determination of PRA were collected via the above-described catheter into chilled tubes containing EDTA·2 $\mathrm{Na}$ (final, $2.7 \mathrm{mM}$ ). 
Plasma was separated by centrifugation at $1200 \times g$ for $15 \mathrm{~min}$ and stored at $-20^{\circ} \mathrm{C}$. The assay mixture (final $\mathrm{pH}$ : 7.4) consisted of $0.5 \mathrm{ml}$ of thawed plasma, $0.4 \mathrm{ml}$ of 0.5 $M$ sodium phosphate buffer containing $14 \mathrm{mM}$ EDTA $\cdot 2$ $\mathrm{Na}$ and $0.3 \%$ neomycin sulfate, $0.075 \mathrm{ml}$ of $20 \mathrm{mM}$ PheAla-Pro as an ACE inhibitor and $0.025 \mathrm{ml}$ of $10 \mathrm{mg} / \mathrm{ml}$ PMSF as an angiotensinase inhibitor. After incubation for $30 \mathrm{~min}$ at $37^{\circ} \mathrm{C}$, the rate of Ang I generation was measured by radioimmunoassay as described above. PRA was expressed as ng Ang I/ml per hr.

Intravenous injection to anesthetized monkeys: $\mathrm{A}$ bolus intravenous injection of $20 \mathrm{mg} / \mathrm{kg}$ and a supplemental infusion of $2.5 \mathrm{mg} / \mathrm{kg}$ per hr of sodium pentobarbital was further applied to ketamine-treated, sodium-depleted monkeys for stable anesthesia. The experiment was started after the blood pressure and heart rate had stabilized. KRI-1314 dissolved in a small amount of $0.1 \mathrm{~N}$ hydrochloride solution and diluted with $5 \%$ glucose solution ( $\mathrm{pH} 5$ ) was injected into a forearm vein at a few doses selected at random from $0.025,0.05,0.1,0.25,0.5,1$ and $3 \mathrm{mg} / \mathrm{kg}$, and then the blood pressure and heart rate were continuously monitored. The vehicle, $5 \%$ glucose solution adjusted to pH 5, was used in a control experiment. Blood samples for PRA assay were collected from the groups treated with vehicle and $0.25,1$ and $3 \mathrm{mg} / \mathrm{kg}$ KRI-1314 just before the injection, at the time of maximal hypotension; at 5 min after the injection, only in a control experiment; and at $30 \mathrm{~min}$ after the injection.

Oral administration to conscious monkeys: Immediately after the implantation of a femoral catheter as described above, the sodium-depleted monkeys were equipped in sitting position with a tailored hard costume made of fiberglass-reinforced plastic (FRP) to immobilize their shoulders and hips and partially restrict the movement of their extremities. The monkeys had been habituated to sitting in this costume and did not appear to be distressed during the experiment. The catheter was connected to a pressure transducer as described above. The experiment was started after the influence of ketamine hydrochloride had disappeared and blood pressure and heart rate had stabilized. Viewing of various programmes on T.V. was planned to obtain stable blood pressure and heart rate. KRI-1314 dissolved in a small amount of $0.1 \mathrm{~N}$ hydrochloride and diluted with $5 \%$ glucose solution $(\mathrm{pH}$ 5) was administered at a dose of 3,10 or $30 \mathrm{mg} / \mathrm{kg}$ into the stomach via a feeding tube, and then the blood pressure and heart rate were recorded continuously. The vehicle, $5 \%$ glucose solution adjusted to $\mathrm{pH} 5$, was used in a control experiment. Blood samples for the measurement of PRA were taken just before and at 1,3 and $5 \mathrm{hr}$ after administration.

Determination of KRI-1314: In a separate experiment, concentrations of KRI-1314 were measured in plasma samples obtained at $0.5,1,2,3,5$ and $7 \mathrm{hr}$ after oral administration of 10 or $30 \mathrm{mg} / \mathrm{kg}$ to conscious, sodiumdepleted Japanese monkeys. Two milliliters of $0.05 \mathrm{M}$ sodium hydroxide solution and $6 \mathrm{ml}$ of benzene were added to $0.2 \mathrm{ml}$ of plasma sample. The mixture was shaken for $10 \mathrm{~min}$ and then centrifuged at $1200 \times \mathrm{g}$ for $10 \mathrm{~min}$. The organic layer was evaporated to dryness, and the residue was redissolved in a mixture of $150 \mu l$ of acetonitrile and distilled water $(1: 1, v / v)$. For the determination of KRI$1314,100-\mu l$ aliquots of this preparation were analyzed by the same HPLC method as described above.

\section{Statistical analyses}

Values are expressed as means \pm S.E.M. Statistical significance was calculated by one-way analysis of variance followed by Dunnett's multiple-range test (24). Probability values of less than 0.05 were defined as significant.

\section{RESULTS}

\section{Inhibition of renin in vitro}

Table 1 summarizes the inhibitory potencies of KRI1314 against PRAs from eight different species. KRI-1314 showed the strongest inhibitory effect against human plasma renin, followed by, in order, Japanese monkey, cynomolgus monkey, rhesus monkey, dog, rabbit, guinea pig and rat plasma renins. The inhibitory potency of KRI1314 for human plasma renin was about $4,11,14,17,28$, 66 and 6600 times as strong as that for Japanese monkey, cynomolgus monkey, rhesus monkey, dog, rabbit, guinea pig and rat plasma renins, respectively; and it was 2.6 times stronger at optimal pH 6.0 than at physiological $\mathrm{pH} 7.4$.

The result of Dixon plot analysis, as shown in Fig. 2, revealed that KRI-1314 inhibits human renin and human tridecapeptide substrate reactions by competitive inhibi-

Table 1. Inhibitory effect of KRI-1314 on the plasma renin activities of various species in vitro

\begin{tabular}{lcccc}
\hline Species & $\mathrm{pH}$ & $\mathbf{n}$ & $\begin{array}{l}\mathrm{IC} \text { (M) } \\
(\mathrm{M})\end{array}$ & $\begin{array}{l}\text { Relative } \\
\text { potency (\%) }\end{array}$ \\
\hline Human & 6.0 & 2 & $1.8 \times 10^{-9}$ & 261 \\
Human & 7.4 & 2 & $4.7 \times 10^{-9} \mathrm{a}$ & 100 \\
Japanese monkey & 7.4 & 4 & $2.0 \times 10^{8}$ & 23.5 \\
Cynomolgus monkey & 7.4 & 2 & $5.1 \times 10^{-8}$ & 9.22 \\
Rhesus monkey & 7.4 & 2 & $5.7 \times 10^{-8}$ & 8.25 \\
Dog & 7.4 & 2 & $7.9 \times 10^{-8} \mathrm{a}$ & 5.95 \\
Rabbit & 7.4 & 2 & $1.3 \times 10^{-7} \mathrm{a}$ & 3.62 \\
Guinea pig & 7.4 & 2 & $3.1 \times 10^{-7}$ & 1.52 \\
Rat & 7.4 & 2 & $3.1 \times 10^{-5}$ & 0.015 \\
\hline
\end{tabular}

: cited from our previous paper (18) for comparison. 


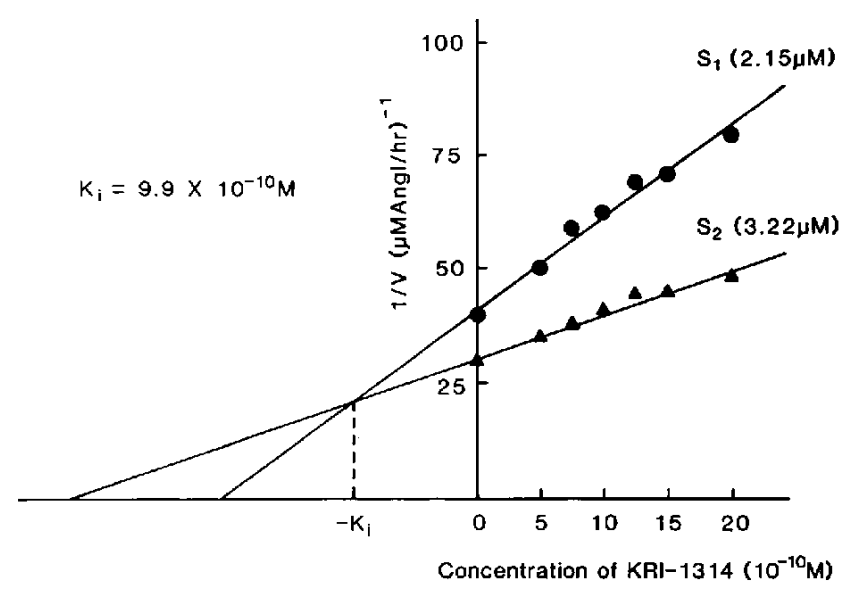

Fig. 2. Inhibition mode and $K_{i}$ value of KRI-1314 on human reninhuman tridecapeptide substrate reaction by Dixon plot analysis. Human tridecapeptide substrate was used at concentrations of 2.15 (O) and $3.22(\Delta) \mu \mathrm{M}$. Each point is the mean of two measurements.

tion, and its $\mathrm{K}_{\mathrm{i}}$ value is $9.9 \times 10^{-10} \mathrm{M}$.

\section{Inhibition of tissue renin-like activities in vitro}

Table 2 depicts the renin-like activities of various tissues from Japanese monkeys and the $\mathrm{IC}_{50}$ values of KRI1314 on these activities. Renin-like activities were highest in the kidney, followed by, in order, the adrenal, heart, lung and aorta. The $\mathrm{IC}_{50}$ values of KRI-1314 on the reninlike activities of these tissues were approximately similar to that obtained against the PRA from the same animal, Japanese monkey, as shown in Table 1. At a concentration of $1 \times 10^{-6} \mathrm{M}$, KRI-1314 produced $85 \%$ or greater inhibition of the renin-like activities in these tissues.

Stability in tissue homogenates from Japanese monkeys

The stability of KRI-1314 (initial concentration: $10^{-4}$ M) in tissue homogenates from Japanese monkeys is shown in Fig. 3. During a 4-hr incubation with the homogenates of liver, lung, small intestine and kidney,

Table 2. Renin-like activities in various tissues from Japanese monkeys and its inhibition by KRI-1314

\begin{tabular}{lcc}
\hline Tissue & $\begin{array}{c}\text { Renin-like activity } \\
\text { (ng Ang I/mg protein per hr) }\end{array}$ & $\begin{array}{c}\mathrm{IC}_{50} \\
\left(\times 10^{-8} \mathrm{M}\right)\end{array}$ \\
\hline Kidney & 403.3 & 2.9 \\
Adrenal & 0.463 & 3.6 \\
Heart & 0.122 & 4.0 \\
Lung & 0.082 & 5.5 \\
Aorta & 0.034 & 4.3 \\
\hline
\end{tabular}

Each value is the mean of two measurements.

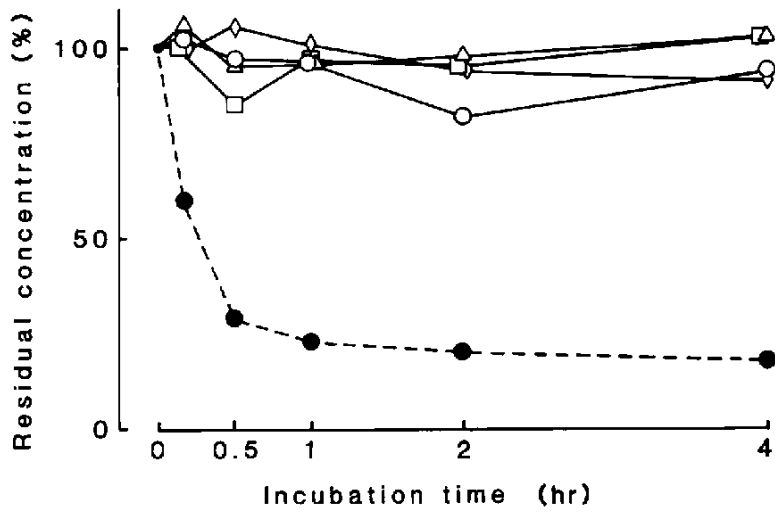

Fig. 3. Stability of KRI-1314 in various tissue homogenates from Japanese monkeys in vitro. Residual concentration of KRI-1314 in the liver $(\bigcirc)$, lung $(\triangle)$, small intestine $(\square)$ and kidney $(\diamond)$ homogenates was calculated as a percentage of the initial content. Synthesized renin substrate Suc-Arg-Pro-Phe-His-Leu-Leu-Val-TyrMCA (O) was used as the reference compound only in the liver homogenate. Each point is the mean of two measurements.

KRI-1314 maintained its initial concentration. On the other hand, a synthesized MCA renin substrate as a reference compound was rapidly degraded by the liver homogenate.

Intravenous administration in anesthetized, sodium-depleted Japanese monkeys

Bolus intravenous injection of KRI-1314 lowered blood pressure in sodium-depleted Japanese monkeys in a dosedependent manner (Fig. 4). Maximal hypotensive responses of $2.0 \pm 0.4(n=4), 5.3 \pm 1.6(n=6), 8.5 \pm 1.9$ $(n=6), \quad 12.6 \pm 3.2(n=5), 13.4 \pm 1.2(n=5), 14.2 \pm 1.2$

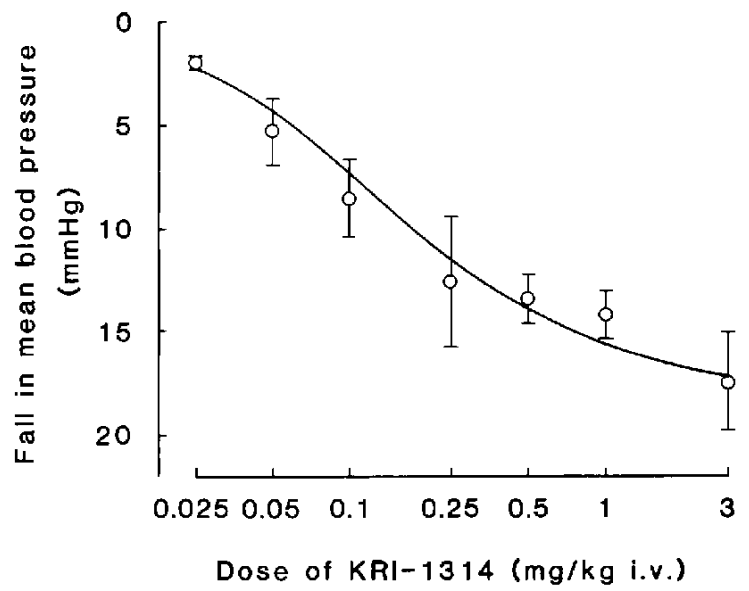

Fig. 4. Dose-response curve for maximal hypotension induced by bolus intravenous injection of $0.025(n=4), 0.05(n=6), 0.1(n=6)$, $0.25(n=5), 0.5(n=5), 1(n=5)$ and $3(n=4) \mathrm{mg} / \mathrm{kg}$ of KRI-1314 to anesthetized, sodium-depleted Japanese monkeys. Vertical bars represent the standard error of the mean. 
$(\mathrm{n}=5)$ and $17.5 \pm 2.4(\mathrm{n}=4) \mathrm{mmHg}$ were attained between 2 and $6 \mathrm{~min}$ after injection of $0.025,0.05,0.1,0.25$, $0.5,1$ and $3 \mathrm{mg} / \mathrm{kg}$, respectively. Figure 5 shows the time course of changes in the blood pressure, heart rate and PRA after intravenous injection of vehicle and KRI-1314. Among the groups treated with vehicle and $0.25,1$ and 3 $\mathrm{mg} / \mathrm{kg} \mathrm{KRI-1314,} \mathrm{there} \mathrm{was} \mathrm{no} \mathrm{significant} \mathrm{difference} \mathrm{in}$ blood pressure, heart rate and PRA levels before injection: $89 \pm 2(n=5), 87 \pm 3(n=5), 88 \pm 3(n=5)$ and $91 \pm 2$ $(\mathrm{n}=4) \mathrm{mmHg}$, respectively, in blood pressure; $125 \pm 7$ $(n=5), 104 \pm 7(n=5), 122 \pm 6(n=5)$ and $134 \pm 4(n=4)$ beats/min, respectively, in heart rate; $18.8 \pm 2.7(n=5)$, $19.0 \pm 5.6(n=5), 22.7 \pm 3.9(n=5)$ and $22.7 \pm 6.0(n=4)$ ng Ang $\mathrm{I} / \mathrm{ml}$ per $\mathrm{hr}$, respectively, in PRA. In the vehicletreated group, the blood pressure, heart rate and PRA remained almost unchanged for $30 \mathrm{~min}$. At the time when the maximal hypotension occurred after injection of 0.25 , 1 and $3 \mathrm{mg} / \mathrm{kg}$ of KRI-1314, the PRA was significantly reduced by $88.9(n=5), 93.0(n=5)$ and $96.9(n=4) \%$,
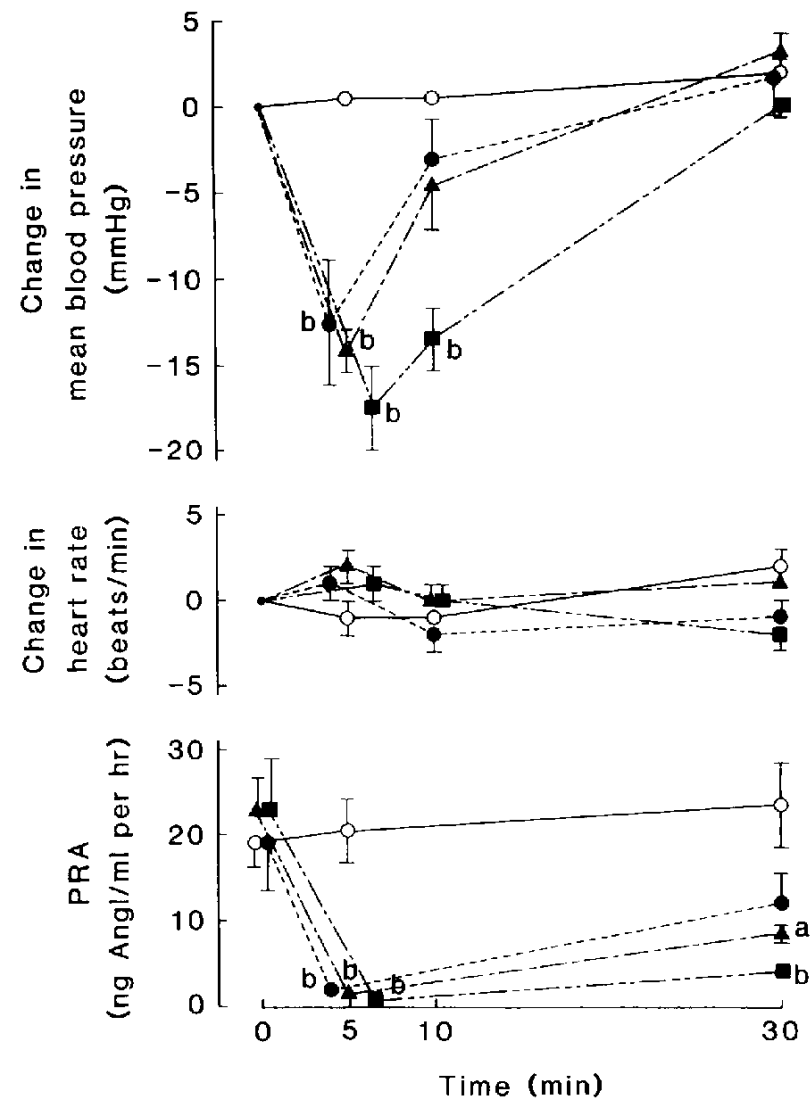

Fig. 5. Effect of intravenous injection of KRI-1314 on mean blood pressure, heart rate and plasma renin activity (PRA) in anesthetized, sodium-depleted Japanese monkeys. KRI-1314 at doses of 0.25 $(n=5, O), \mathrm{l}(\mathrm{n}=5, \boldsymbol{\Delta})$ and $3(\mathrm{n}=4, \square) \mathrm{mg} / \mathrm{kg}$ was compared with the vehicle $(n=5, O)$. Vertical bars represent the standard error of the mean. ${ }^{a}$ and ${ }^{b}$ : significant difference $(\mathrm{P}<0.05$ and $\mathrm{P}<0.01$, respectively) from the vehicle-treated group. respectively. On the other hand, the blood pressure at 30 min after injection had completely returned to the initial levels, while the PRA was still suppressed by $36.3(n=5)$, $63.0(n=5)$ and $81.9(n=4) \%$ in a dose-dependent manner. A reflective increase in heart rate due to blood pressure lowering was not observed.

\section{Oral administration in conscious, sodium-depleted Japa- nese monkeys}

The time course of changes in blood pressure and PRA after oral administration of KRI-1314 and its vehicle are shown in Fig. 6. Prior to administration of the vehicle or 3,10 or $30 \mathrm{mg} / \mathrm{kg}$ of KRI-1314, the groups showed no significant differences in blood pressure: $105 \pm 5(n=8)$, $100 \pm 5(n=6), 104 \pm 3(n=5)$ and $111 \pm 4(n=5) m m H$, respectively; heart rate: $194 \pm 4(n=8), 183 \pm 4(n=6)$, $190 \pm 3(n=5)$ and $183 \pm 12(n=5)$ beats/min, respectively; and PRA: 59.5 $\pm 6.0(\mathrm{n}=8), 39.9 \pm 1.5 \quad(\mathrm{n}=6)$, $49.7 \pm 10.5(\mathrm{n}=5)$ and $59.5 \pm 4.5(\mathrm{n}=5) \mathrm{ng}$ Ang $\mathrm{I} / \mathrm{ml}$ per hr, respectively. After oral administration of the vehicle,

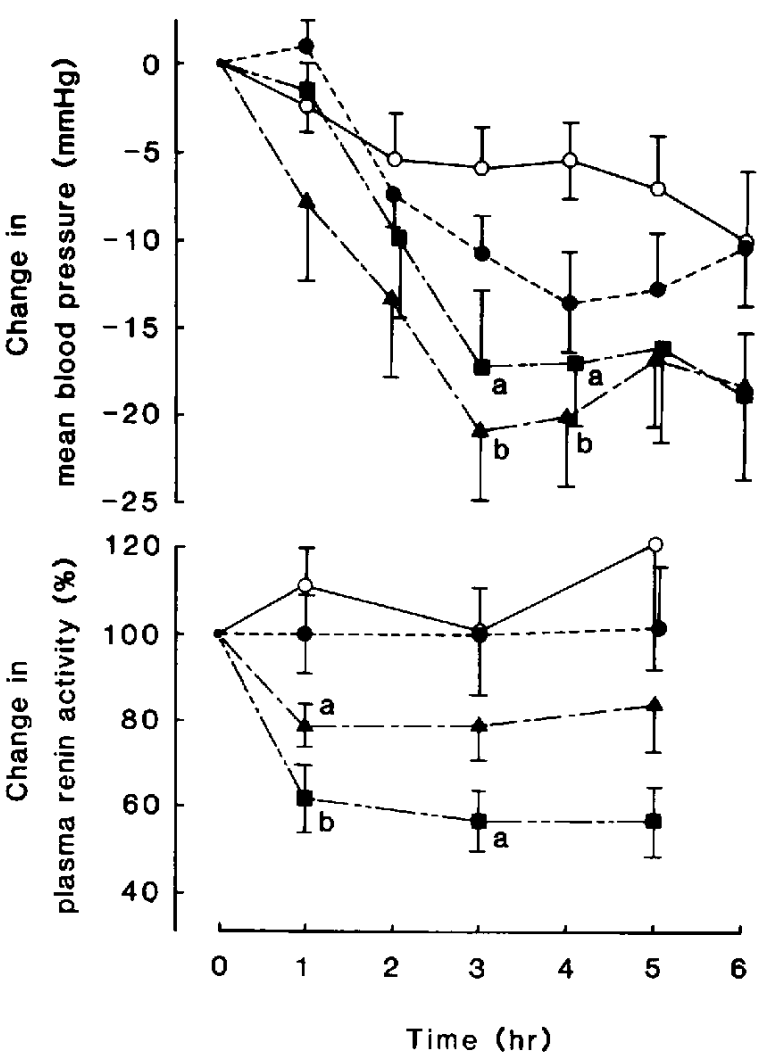

Fig. 6. Effect of oral administration of KRI-1314 on mean blood pressure and plasma renin activity (PRA) in conscious, sodiumdepleted Japanese monkeys. KRI-1314 at doses of $3(\mathrm{n}=6, \mathrm{O}), 10$ $(\mathrm{n}=5, \Delta)$ and $30(\mathrm{n}=5, \square) \mathrm{mg} / \mathrm{kg}$ was compared with the vehicle $(n=8, \bigcirc)$. Vertical bars represent the standard error of the mean. ${ }^{a}$ and ${ }^{b}$ : significant difference $(P<0.05$ and $P<0.01$, respectively) from the vehicle-treated group. 


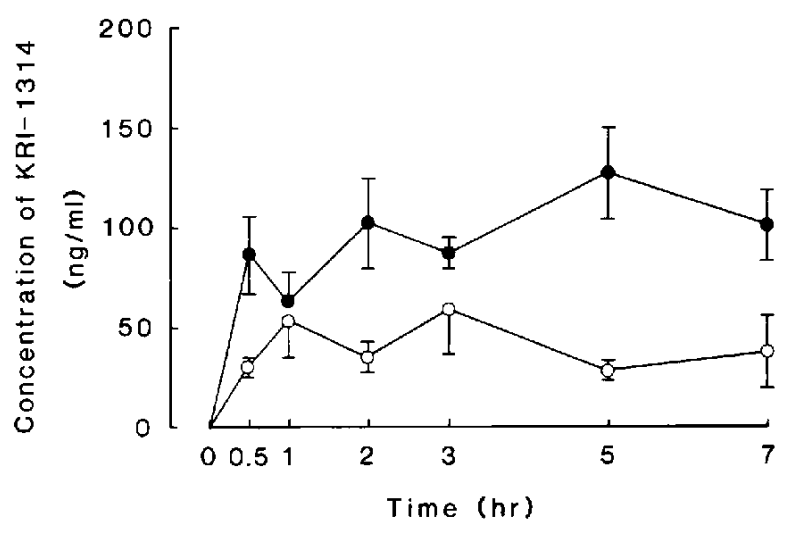

Fig. 7. Plasma concentration of KRI-1314 after oral administration of $10(n=6, \bigcirc)$ and $30(n=4, \bigcirc) \mathrm{mg} / \mathrm{kg}$ of the compound to conscious, sodium-depleted Japanese monkeys. Vertical bars represent the standard error of the mean.

blood pressure decreased slightly, heart rate remained almost unchanged and PRA tended to increase, but not significantly. At an oral dose of $3 \mathrm{mg} / \mathrm{kg}, \mathrm{KRI}-1314 \mathrm{did}$ not show a clear effect in lowering blood pressure and PRA. On the other hand, oral doses of 10 and $30 \mathrm{mg} / \mathrm{kg}$ of KRI-1314 were significantly effective in lowering blood pressure and PRA. Both doses, although causing a similar maximal hypotension of approximately $20 \mathrm{mmHg}$ during the 3- to 4-hr period following administration, induced dose-dependent suppression in PRA. At a dose of $10 \mathrm{mg} / \mathrm{kg}$, KRI-1314 suppressed PRA by $24.7 \pm 5.9$ $(n=5), 24.2 \pm 8.5(n=5)$ and $13.2 \pm 15.3(n=5) \%$ at 1,3 and $5 \mathrm{hr}$ after administration, respectively; and at a dose of $30 \mathrm{mg} / \mathrm{kg}$, it suppressed PRA by $37.8 \pm 8.1(\mathrm{n}=5)$, $42.5 \pm 7.1(n=5)$ and $42.6 \pm 8.1(n=5) \%$, respectively. In the early stage, e.g., $1 \mathrm{hr}$ after administration, there was no distinguishable fall in blood pressure, although the PRAs have already been significantly suppressed. KRI1314 at doses of 3,10 and $30 \mathrm{mg} / \mathrm{kg}$ did not show any significant effect on heart rate as in the intravenous experiment.

In a separate experiment, KRI-1314 was detected in the plasma in a dose-dependent manner after oral administration of 10 and $30 \mathrm{mg} / \mathrm{kg}$ to conscious Japanese monkeys (Fig. 7). The plasma concentrations of KRI-1314 lasted for at least $7 \mathrm{hr}$ after oral administration.

\section{DISCUSSION}

In the present study, we demonstrated that: 1) KRI1314 strongly and selectively inhibited human and monkey renins including the tissue renin-like activities from Japanese monkeys; 2) Both intravenous and oral administration of KRI-1314 lowered the blood pressure and PRA without affecting the heart rate in sodium- depleted Japanese monkeys; 3) In the time course, the magnitude of fall in blood pressure did not always run parallel with the degree of suppression in PRA, suggesting that non-circulating renin may play an important role in the depressor action of KRI-1314.

In the in vitro experiment, our kinetic study on enzyme inhibition indicated that KRI-1314 strongly inhibited purified human renin and the human synthetic tridecapeptide substrate reaction by competitive inhibition. Rich (25) suggested that when a pepstatin-derived inhibitor approaches a renin molecule, the hydroxy group of the statine moiety will probably be replaced with a water molecule, which had combined with the catalytic site, resulting in the strong binding of the inhibitor to a renin molecule. This hypothesis may also be well suited for our norstatinederived inhibitor KRI-1314. KRI-1314 strongly inhibited PRAs from humans and monkeys but acted weakly on those from dogs, rabbits, guinea pigs and rats. In Japanese monkeys, KRI-1314 also exhibited approximately equal inhibition against the renin-like activities of various tissues. These results indicate that KRI-1314 possesses a high degree of species specificity for primate renins, similar to other renin inhibitors such as CGP 38560 (26), ES 6864 (27) and Ro $42-5892$ (28). The species specificity of these inhibitors may be presumably due to differences in the three dimensional structures of individual renins. Because of the species specificity, Japanese monkeys, which are close to humans with regard to PRA inhibition, were employed in the in vivo experiments.

Intravenous bolus injection of KRI-1314 produced a dose-dependent fall in blood pressure and a simultaneous decrease in PRA in anesthetized, sodium-depleted Japanese monkeys. Under the conditions of this experiment, the magnitude of blood pressure regulated by renin was estimated to be about $18 \mathrm{mmHg}$, almost identical to the value obtained in the oral experiment. KRI-1314 did not affect heart rate. This indicates that KRI-1314 did not act as a mere vasodilator, whose blood pressure lowering effect would cause tachycardia due to the homeostatic maintenance of arterial blood pressure (28). The lack of tachycardia might be due to the reduction of Ang II which inhibits vagal nerve activity and facilitates sympathetic nerve activity $(29-31)$. Although the results from the intravenous experiment indicate that the renin inhibitor KRI-1314 is a promising candidate for treating human hypertension based on the acceleration of the RAS, a very important problem, as shown below, remains to be solved, if we attempt to apply KRI-1314 to the treatment of human hypertension.

If antihypertensives are to be used on a daily basis, the availability of the oral administration route must be taken into consideration. However, numerous investigations reported to date have shown that the bioavailability of 
renin inhibitors is rather low. For example, the oral bioavailability of both CGP $38560 \mathrm{~A}$ and A- 64662 was estimated to be less than $1 \%$ in humans $(32,33)$, whereas the value of BW-175, estimated in rats, ranged from 2.8 to $9.7 \%$ (34). No other renin inhibitors have demonstrated good oral bioavailability in non-human primate models. The limited bioavailability of renin inhibitors arises from poor absorption, metabolic instability and rapid biliary excretion, presumably due to the peptidic nature, high molecular weight and low water solubility of these substances. Thus, we concentrated on designing the new renin inhibitor KRI-1314 so as to enhance its oral efficacy.

The peptidic renin inhibitors so far reported have been thought to be easily degraded by digestive proteases, particularly chymotrypsin, which is specific to aromatic Lamino acids, e.g., tryptophan, tyrosine and phenylalanine. Since the recognition of $\mathrm{Phe}^{8}$ by chymotrypsin is lost by replacing the $\alpha \mathrm{NH}$ of Phe with oxygen or carbon, the $\mathrm{N}$-terminus of a natural amino acid histidine $\left(\mathrm{P}_{2}\right.$ position) was converted to the derivative of a succinic acid, which has a retro-inverso amide bond. This conversion is found to be useful for protecting the Phe-His peptide bond $\left(\mathrm{P}_{3}-\mathrm{P}_{2}\right.$ site) against hydrolysis by chymotrypsin without losing hydrogen bonds between the inhibitor and the active center of renin (35). Our study demonstrated that KRI-1314 is not decomposed after a 4-hr incubation with various tissue homogenates from Japanese monkeys, suggesting that the compound is extremely resistant to such enzymatic degradation in vivo. Furthermore, it is known that the higher hydrophobicity of renin inhibitors causes not only stronger potency with regard to renin inhibition but also, unfortunately, lower absorbability from the intestinal tract and greater susceptibility to the hepatic first-pass effect. The latter two are responsible for the limitation in oral availability. Therefore, to improve the water solubility without losing the inhibitory potency for renin, a hydrophilic morpholine group was incorporated into the N-terminus of KRI-1314 in place of the proline at the $\mathrm{P}_{4}$ position. With respect to the molecular weight, that of KRI-1314 is relatively low as compared with other renin inhibitors. Although we have not estimated the exact oral bioavailability of KRI-1314, our results from the oral experiment suggest that the bioavailability of the compound is much improved as compared with other renin inhibitors.

Oral administration of 10 and $30 \mathrm{mg} / \mathrm{kg} \mathrm{KRI}-1314$ to conscious, sodium-depleted Japanese monkeys significantly lowered their PRA and blood pressure, although at a dose level of $3 \mathrm{mg} / \mathrm{kg}$, KRI-1314 did not show any significant effect. This indicates that KRI-1314 is an orally effective candidate for the treatment of renin-dependent hypertension. KRI-1314 did not induce any significant change in heart rate as in the intravenous experiment. The decrease in PRA showed a dose-dependency among the three dose levels, but the magnitude of reduction in the blood pressure after administration of 10 and $30 \mathrm{mg} / \mathrm{kg}$ did not. Since the maximal net fall in blood pressure at 3 $\mathrm{hr}$ after oral administration of $10 \mathrm{mg} / \mathrm{kg}$ was nearly similar to the value obtained in the intravenous experiment in this study and in the oral experiments on other renin inhibitors such as CGP 29287 (36), KRI-1230 (14), U-71038 (37) and ES-8891 (38) at a dose of 100, 30, 50 and 30 $\mathrm{mg} / \mathrm{kg}$, respectively, the maximal hypotensive response to KRI-1314 is thought to already be attained at a dose level of $10 \mathrm{mg} / \mathrm{kg}$. Furthermore, it is difficult to precisely elucidate the dose-dependency of hypotensive action within the limited range of $20 \mathrm{mmHg}$ in conscious animals, even if the monkeys were presented with standardized audio and visual stimuli such as watching TV in an attempt to stabilize blood pressure and heart rate. As KRI-1314 is five times more effective in vitro in inhibiting renin from humans than from monkeys, KRI-1314 can be expected to exert an even stronger hypotensive effect in clinical trials.

The absorption of KRI-1314 from the digestive tract, including the enterohepatic circulation, appears to be relatively low, slow and continuous because the plasma concentrations of the compound remained at constant levels of about 50 and $100 \mathrm{ng} / \mathrm{ml}$ for at least $7 \mathrm{hr}$ after oral administration of 10 and $30 \mathrm{mg} / \mathrm{kg}$, respectively. This unique pattern in absorption was quite consistant with the time course of reduction in PRA at the same dose levels, but fairly different from the results from other renin inhibitors, e.g., ES 6864 (27), whose plasma levels were not correlated to the time course of PRA. This difference may be due in part to the difference in the assay method of PRA and to whether the metabolites of the compounds have sufficient potency. The remarkable in vivo durability and enzyme-resistant property of KRI-1314, despite its relatively low plasma levels, are thought to contribute to its lowering of PRA and blood pressure which lasted for more than 5 or $6 \mathrm{hr}$.

At $1 \mathrm{hr}$ after oral administration of KRI-1314, the blood pressure remained almost unchanged, while PRA was already suppressed significantly. In contrast, at $3 \mathrm{hr}$ after oral administration, the blood pressure was maximally lowered, while the reduction in PRA remained essentially unchanged and was nearly equal to that at $1 \mathrm{hr}$ after administration. This difference in response between PRA and blood pressure was also observed when KRI1314 was administered intravenously. Thirty minutes after injection, the blood pressure had already returned to the original levels, while PRA was still suppressed. These results indicate that there is no direct relationship between the degree of suppression in PRA and the magnitude of lowered blood pressure in sodium-depleted Japanese mon- 
keys. Blaine et al. (39) examined the relationship between the degree of suppression in PRA and the magnitude of hypotension using a statine-containing renin inhibitory peptide (SCRIP) in sodium-depleted dogs. They also concluded that a relationship does not necessarily exist between these values. In this regard, the following explanations can be offered.

A first issue of concern is whether or not the assay method used to assess PRA is proper. Jeunemaitre et al. (40) reported that the conventional PRA assay method used in the studies of a large number of renin inhibitors, which is very similar to the method used in this study, grossly overestimated the in vivo duration of PRA inhibitory action of the renin inhibitors and was not appropriate for quantifying the in vivo renin inhibition. This may result in a dissociation between the degree of suppression in PRA and the magnitude of lowered blood pressure. They added that PRA obtained by an Ang I antibody trapping method came relatively closer to plasma Ang I and II levels, although it still differed. Since this Ang I antibody trapping method invented by Poulsen and Jørgensen (41) protects Ang I from degradation by the addition of Ang I antibodies instead of angiotensinase inhibitors such as hydroxyquinoline, PMSF or diisopropylfluorophosphate to the reaction mixture, the in vitro condition may considerably resemble the physiological environment. In contrast to their results, however, Fischli et al. (28) reported that the PRA measured by the same Ang I antibody trapping method did not change in parallel with reductions in Ang I, Ang II and blood pressure at either 1 or $4 \mathrm{hr}$ after oral administration of Ro 42-5892 to squirrel monkeys. Therefore, to date there is no adequate PRA methodology to explain the dissociation. In our study, the pattern of suppression in PRA was closely related to that of plasma concentration of KRI-1314. This implies that the assay method used for PRA in this experiment can thoroughly explain the effect of KRI-1314 on RAS in plasma. We therefore suggest that the degree of suppression in PRA is a good reflection of the plasma levels of the renin inhibitor in a limited concentration range and is not necessarily related to the magnitude of lowered blood pressure.

Second, it is indicated that renin pools other than plasma renin play an important role in the maintenance of blood pressure (42-46). Therefore, the magnitude of hypotension due to renin inhibition is assumed to be more closely related to the degree of suppression in these noncirculating renin components than that in the circulating one. Wood et al. (47) showed that renin-like activity in the aorta was significantly reduced after chronic administration of CGP 29287 to normotensive sodium-depleted marmosets. In the present study, we found that renin-like activities exist in tissues of Japanese monkeys, namely, kidney, heart, lung, adrenal and aorta, and that KRI-
1314 strongly inhibits these tissue renin-like activities with $\mathrm{IC}_{50}$ values of $2.9 \times 10^{-8}$ to $5.5 \times 10^{-8} \mathrm{M}$. KRI-1314 was also shown to be stable in various tissue homogenates from Japanese monkeys in in vitro experiments and was shown to be detected continuously in plasma after oral administration to Japanese monkeys. Therefore, if the tissue concentrations of this compound after oral administration of 10 and $30 \mathrm{mg} / \mathrm{kg}$ could be maintained in a range similar to plasma levels of about 50 and $100 \mathrm{ng} / \mathrm{ml}$ $\left(0.8 \times 10^{-7}\right.$ and $\left.1.5 \times 10^{-7} \mathrm{M}\right)$, respectively, the tissue renin-like activity, which might regulate blood pressure locally, can be sufficiently inhibited. More recently, Mizuno et al. (48) reported that immunoreactive Ang II released from isolated perfused human umbilical cord veins was reduced by $A C E$ inhibitors and renin inhibitors. In their results, $10^{-9}$ to $10^{-6} \mathrm{M}$ of KRI-1314 showed a significant suppression in Ang II generation in a doserelated fashion, but the non-specific renin inhibitor $N$ acetyl-pepstatin suppressed Ang II generation by only $24 \%$ at $10^{-5} \mathrm{M}$. The greater potency of KRI-1314 in this preparation, compared to that of $N$-acetyl-pepstatin, may be mainly due to its high species specificity for human renin and partially due to its good balance of lipophilicity and water solubility. These results directly demonstrate that the human-specific renin inhibitor KRI-1314 can suppress renin-like activity in human vascular tissue even at low concentrations. Thus, tissue renin-like enzyme might contribute to the depressor mechanism of KRI-1314 and might cause the dissociation between suppression in PRA and fall in blood pressure.

Lastly, it has been known that in RAS, Ang II is a physiologically active substance that directly affects the contraction of blood vessels. Accordingly, even if the renin activity should be suppressed by a renin inhibitor, blood pressure can not be lowered without a reduction in the level of the pressor peptide Ang II. A lowering of blood pressure based on the inhibition of RAS is ultimately related to the suppression of the Ang II level. This requires further investigation. Also, the depressor mechanism of renin inhibitors is still unclear and requires further study.

In summary, it can be concluded that KRI-1314 is a stable and selective inhibitor of human and monkey renins, showing a depressor action without affecting the heart rate by both intravenous and oral administration to sodium-depleted Japanese monkeys, and can become an useful tool for clarifying the pathophysiology of hypertension.

\section{Acknowledgments}

The authors wish to express their thanks to Prof. Kazuo Murakami (Institute of Applied Biochemistry, University of Tsukuba, Ibaraki, Japan) for supplying the purified human renin used in this study and to Kissei Pharmaceutical Co., Ltd. (Matsumoto, Japan) for sup- 
plying the KRI-1314 and for their constant assistance and technical discussions.

\section{REFERENCES}

1 Coulter, D.M. and Edwards, I.R.: Cough associated with captopril and enalapril. Br. Med. J. 294, $1521-1523$ (1987)

2 Morice, A.H., Lowry, R., Brown, M.J. and Higenbottam, T.: Angiotensin-converting enzyme and the cough reflex. Lancet 2 , 1116-1118 (1987)

3 Wood, S.M., Mann, R.D. and Rawlins, M.D.: Angio-oedema and urticaria associated with angiotensin converting enzyme inhibitors. Br. Med. J. 294, 91 -92 (1987)

4 Skidgel, R.A. and Erdös, E.G.: The broad substrate specificity of human angiotensin I converting enzyme. Clin. Exp.-Theory and Practice A9, 243-259 (1987)

5 Smeby, R.R., Sen, S. and Bumpus, F.M.: A naturally occurring renin inhibitor. Circ. Res. 20, Supp. II, II $129-$ II 134 (1967)

6 Umezawa, H., Aoyagi, T., Morishima, H., Matsuzaki, M., Hamada, M. and Takeuchi, T.: Pepstatin, a new pepsin inhibitor produced by actinomycetes. J. Antibiot. 23, 259-262 (1970)

7 Miyazaki, M., Hosoki, K. and Yamamoto, K.: Renin inhibition by synthetic phosphatidyl and phosphorylethanolamines. Japan. Circ. J. 40, 901-910 (1976)

8 Hosoki, K., Miyazaki, M. and Yamamoto, K.: Renin inhibitory effect of 2-[4-(4'-chlorophenoxy)phenoxyacetylamino]ethylphosphorylethanolamine (PE-104) in vitro and in vivo. J. Pharmacol, Exp. Ther. 203, 485-492 (1977)

9 Miyazaki, M., Okunishi, H., Komori, T. and Yamamoto, K.: Renin inhibitory effect of $\mathrm{N}$-acetyl-pepstatin. Japan. J. Pharmacol. 28, 171-174 (1978)

10 Szelke, M., Leckie, B., Hallett, A., Jones, D.M., Sueiras, J., Atrash, B. and Lever, A.F.: Potent new inhibitors of human renin. Nature 299, $555-557$ (1982)

11 Boger, J., Lohr, N.S., Ulm, E.H., Poe, M., Blaine, E.H., Fanelli, G.M., Lin, T.Y., Payne, L.S., Schorn, T.W., LaMont, B.I., Vassil, T.C., Stabilito, I.I., Veber, D.F., Rich, D.H. and Bopari, A.S.: Novel renin inhibitors containing the amino acid statine. Nature 303, $81-84$ (1983)

12 Marciniszyn, J., Hartsuck, J.A. and Tang, J.: Mode of inhibition of acid proteases by pepstatin. J. Biol. Chem. 251, 7088-7094 (1976)

13 Toda, N., Miyazaki, M., Etoh, Y., Kubota, T. and Iizuka K.: Human renin inhibiting dipeptide. Eur. J. Pharmacol. 129, $393-396$ (1986)

14 Miyazaki, M., Toda, N., Etoh, Y., Kubota, T. and Iizuka, K.: Newly synthesized, potent human renin inhibitor. Japan. J. Pharmacol. 40, Supp. 70P (1986)

15 Iizuka, K., Kamijo, T., Kubota, T., Akahane, K., Umeyama, $H$. and Kiso, Y.: New human renin inhibitors containing an unnatural amino acid, norstatine. J. Med. Chem. 31, 701-704 (1988)

16 Harada, H., Iizuka, K., Kamijo, T., Akahane, K., Yamamoto, R., Nakano, Y., Tsubaki, A., Kubota, T., Shimaoka, I., Umeyama, H. and Kiso, Y.: Synthesis of human renin inhibitory peptides, angiotensinogen transition-state analogs containing a retro-inverso amide bond. Chem. Pharm. Bull. (Tokyo) 38, 3042-3047 (1990)

17 Iizuka, K., Kamijo, T., Harada, H., Akahane, K., Kubota, T., Umeyama, H., Ishida, T. and Kiso, Y.: Orally potent human renin inhibitors derived from angiotensinogen transition state: design, synthesis, and mode of interaction. J. Med. Chem. 33, 2707-2714 (1990)

18 Miyazaki, M., Etoh, Y., lizuka, K. and Toda, N.: An orally active renin inhibitor: Cyclohexylnorstatine-containing dipeptide (KRI-1314). J. Hypertens. 7, Supp. 2, S25-S27 (1989)

19 Almquist, R.G., Chao, W., Ellis, M.E. and Johnson, H.L.: Synthesis and biological activity of a ketomethylene analogue of a tripeptide inhibitor of angiotensin converting enzyme. J. Med. Chem. 23, 1392-1398 (1980)

20 Yokosawa, H., Holladay, L.A., Inagami, T., Haas, E. and Murakami, K.: Human renal renin. J. Biol. Chem. 255, 3498-3502 (1980)

21 Dixon, M. and Webb, E.C.: Enzyme, 3rd ed., pp. 365-368, Longman, London (1978)

22 Skinner, S.L.: Improved assay methods for renin "Concentration" and "Activity" in human plasma. Circ. Res. 20, 391-402 (1967)

23 Bradford, M.M.: A rapid and sensitive method for the quantitation of microgram quantities of protein utilizing the principle of protein-dye binding. Anal. Biochem. 72, 248-254 (1976)

24 Dunnett, C.W.: New tables for multiple comparisons with a control. Biometrics 20, 482-491 (1964)

25 Rich, D.H.: Pepstatin-derived inhibitors of aspartic proteinases. A close look at an apparent transition-state analogue inhibitor. J. Med. Chem. 28, 263-273 (1985)

26 Wood, J.M., Criscione, L., de Gasparo, M., Bühlmayer, P., Rüeger, H., Stanton, J.L., Jupp, R.A. and Kay, J.: CGP 38560: Orally active, low-molecular-weight renin inhibitor with high potency and specificity. J. Cardiovasc. Pharmacol. 14, $221-226$ (1989)

27 Hiwada, K., Kokubu, T., Murakami, E., Muneta, S., Morisawa, Y., Yabe, Y., Koike, H. and Iijima, Y.: A highly potent and long-acting oral inhibitor of human renin. Hypertension 11, $708-712(1988)$

28 Fischli, W., Clozel, J.P., Amrani, K.E., Wostl, W., Neidhart, W., Stadler, H. and Branca, Q.: Ro 42-5892 is a potent orally active renin inhibitor in primates. Hypertension 18, 22-31 (1991)

29 Potter, E.K.: Angiotensin inhibits action of vagus nerve at the heart. Br. J. Pharmacol. 75, 9-11 (1982)

30 Zimmerman, B.G., Sybertz, E.J. and Wong, P.C.: Interaction between sympathetic and renin-angiotensin system. J. Hypertens. 2, 581-587 (1984)

31 Campbell, B.C., Sturani, A. and Reid, J.L.: Evidence of parasympathetic activity of the angiotensin converting enzyme inhibitor, captopril, in normotensive man. Clin. Sci. 68, 49-56 (1985)

32 de Gasparo, M., Cumin, F., Nussberger, J., Guyenne, T.T., Wood, J.M. and Menard, J.: Pharmacological investigations of a new renin inhibitor in normal sodium-unrestricted volunteers. Br. J. Clin. Pharmacol. 27, 587-596 (1989)

33 Kleinert, H.D., Luly, J.R., Bopp, B.A., Verburg, K.M., Hoyos, P.A., Karol, M.D., Plattner, J.J., Luther, R.R. and Stein, H.H.: Profile of the renin inhibitor, enalkiren (abbott64662). Cardiovasc. Drug Rev. 8, 203-219 (1990)

34 Morishima, H., Koike, Y., Nakano, M., Atsuumi, S., Tanaka, S., Funabashi, H., Hashimoto, J., Sawasaki, Y., Mino, N., Nakano, M., Matsushima, K., Nakamichi, K. and Yano, M.: A novel nonpeptidic, orally active renin inhibitor. Biochem. 
Biophys. Res. Commun. 159, $999-1005$ (1989)

35 Iizuka, K., Kamijo, T., Harada, H., Akahane, K., Kubota, T., Shimaoka, I., Umeyama, H. and Kiso, Y.: New human renin inhibitory peptides: angiotensinogen transition-state analogues containing novel leu-val replacement and a retro-inverso amide bond. Chem. Pharm. Bull. (Tokyo) 36, 2278-2281 (1988)

36 Wood, J.M., Gulati, N., Forgiarini, P., Fuhrer, W. and Hofbauer, K.G.: Effects of a specific and long-acting renin inhibitor in the marmoset. Hypertension 7, 797-803 (1985)

37 Pals, D.T., Thaisrivongs, S., Lawson, J.A., Kati, W.M., Turner, S.R., DeGraaf, G.L., Harris, D.W. and Johnson, G.A.: An orally active inhibitor of renin. Hypertension 8, 1105-1112 (1986)

38 Kokubu, T., Hiwada, K., Murakami, E., Muneta, S., Kitami, Y. and Salmon, P.F.: ES-8891, an orally active inhibitor of human renin. Hypertension 15, 909-913 (1990)

39 Blaine, E.H., Schorn, T.W. and Boger, J.: Statine-containing renin inhibitor. Dissociation of blood pressure lowering and renin inhibition in sodium-deficient dogs. Hypertension 6, Supp. I, I 111 - I 118 (1984)

40 Jeunemaître, X., Ménard, J., Nussberger, J., Guyene, T.T., Brunner, H.R. and Corvol, P.: Plasma angiotensins, renin, and blood pressure during acute renin inhibition by CGP $38560 \mathrm{~A}$ in hypertensive patients. Am. J. Hypertens. 2, 819-827 (1989)

41 Poulsen, K. and Jørgensen, J.: An easy radioimmunological microassay of renin activity, concentration and substrate in human and animal plasma and tissues based on angiotensin I trap- ping by antibody. J. Clin. Endocrinol. Metab. 39, 816-825 (1974)

42 Re, R.N., Fallon, J.T, Dzau, V.J., Quay, S. and Haber, E.: Renin synthesis by canine aortic smooth muscle cells in culture. Life Sci. 30, 99- 106 (1982)

43 Ganten, D., Hermann, K., Unger, T. and Lang, R.E.: The tissue renin-angiotensin systems: focus on brain angiotensin, adrenal gland and arterial wall. Clin. Exp. Hypertens. A5, $1099-1118$ (1983)

44 Dzau, V.J.: Significance of the vascular renin-angiotensin pathway. Hypertension 8, 553-559 (1986)

45 Saito, H., Nakamaru, M., Ogihara, T., Rakugi, H., Kumahara, Y., Shimamoto, K., Miyazaki, M. and Inagami, T.: Renin inhibitor and converting enzyme inhibitors suppress vascular angiotensin II. Hypertension 13, $749-753$ (1989)

46 Wood, J.M., Baum, H.P., Carleton, J. and Dzau, V.J.: Inhibition of renin-like activity in marmoset tissues by the renin inhibitor CGP 29 287. J. Hypertens. 5, Supp. 2, S67-S69 (1987)

47 Wood, J.M., Whitfield, S.L., Baum, H.P and Jobber, R.A.: Effects of chronic administration of a renin inhibitor on reninlike activity in marmoset tissues. Abstract of the 12th Scientific Meeting of the International Society of Hypertension, No. 1313, Kyoto (1988)

48 Mizuno, K., Niimura, S., Tani, M., Haga, H., Inagami, T. and Fukuchi, S.: Direct proof for local generation and release of angiotensin II in peripheral human vascular tissue. Am. J. Hypertens. 4, 67S-72S (1991) 